\title{
A PESSOA JURIDICA COMO SUJEITO DE DIREITOS HUMANOS
}

\section{THE LEGAL PERSON AS A HUMAN RIGHTS SUBJECT}

\section{RICARDO HASSON SAYEG}

Doutor, Mestre e Livre-Docente. Professor de Direito Econômico e Direitos Humanos na PUCSP. Membro do Conselho Superior da CAPES.

WAGNER BALERA

Mestre, Doutor e Livre-Docente. Professor Titular de Direitos Humanos na PUCSP. Conselheiro do Instituto dos Advogados de São Paulo.

\section{RESUMO}

O presente texto pretende estabelecer que a pessoa jurídica, em suas distintas expressões, pode e deve ser considerada como sujeito de direitos humanos. Analisando distintas posições relacionais busca demonstrar o distinto status jurídico que, tanto em perspectiva substancial quanto processual, pode ter reconhecidos pelas instancias administrativa e jurisdicional como titulares de certos direitos e como destinatárias da proteção jurídica inerente aos direitos humanos.

PALAVRAS-CHAVE: Sujeito de Direito; Pessoa; Pessoa Jurídica; Direitos Humanos; Capitalismo Humanista; Direito Quântico.

\section{ABSTRACT}

The present text intends to establish that the juridical person, in its different expressions, can and should be considered as subject of human rights. Analyzing different relational positions, it seeks to demonstrate the distinct legal status that, both 
in a substantive and procedural perspective, can be recognized by the administrative and jurisdictional instances as holders of certain rights and as recipient of the legal protection inherent in human rights.

KEYWORDS: Subject of law; person; legal person; Human Rights; Humanist Capitalism; Quantum Law.

\section{INTRODUÇÃO}

A partir de um caso concreto submetido à apreciação da Corte Interamericana de Direitos Humanos, é de se indagar qual o conceito de pessoa que deve prevalecer naquele âmbito.

É certo que, tal conceito, depende da reflexão primeira a respeito do atributo inerente à pessoa. Vale dizer, aquela qualidade sem a qual a pessoa não poderia ser considerada como tal. Referimo-nos à noção de dignidade.

Estão de tal modo interligadas as noções de pessoa e de dignidade como, a seu modo, estão interligadas a forma e o mármore em uma estátua.

Por dignidade, a partir da investigação da origem da palavra (dignitas) se entende o valor, a distinção, o princípio em que se funda a conduta. A expressão significa, para este contexto, o reconhecimento social do agir de alguém. Tem dignidade quem atua embasado pelos valores morais que informam a conduta, consoante os objetivos maiores da vida individual e social.

Sob a perspectiva filosófica, mais particularmente a de IMMANUEL KANT (Fundamentação da Metafísica dos Costumes) toda a pessoa é dotada de valor em si mesmo e tal valor corresponde à sua dignidade. Nessa medida, o Mestre de Königsberg exara o célebre imperativo prático: "Age de tal maneira que uses a humanidade, tanto na tua pessoa como na pessoa de qualquer outro, sempre e simultaneamente como fim e nunca simplesmente como meio". (1980, p. 229). E, na mesma linha de raciocínio, argumenta: "Age sempre segundo aquela máxima cuja universalidade como lei possas querer ao mesmo tempo". 
Sempre, pois, que a humanidade venha a atuar em busca dos fins que lhe são próprios fará valer a sua dignidade.

Eis a razão pela qual a dignidade é a pedra angular em que se assenta a Declaração Universal dos Direitos Humanos, proclamada pela Assembleia Geral das Nações Unidas em 1948.

E, a seu modo, tal conceito perpassa todos os demais Documentos Internacionais de Direitos Humanos, particularmente a Convenção Americana de Direitos Humanos (Pacto de San Jose de Costa Rica).

Ora, sendo certo que os Direitos Humanos representam vero consenso social desta época, denominador comum da sociedade humana, podem esses mesmos direitos ser reconhecidos como aquela "máxima" a que se refere KANT.

Representativos da lei universal que congloba assim os direitos individuais quanto os direitos econômicos, sociais e culturais, devem tais direitos ganhar efetividade integral.

Configuram, os Direitos Humanos, ademais, a suma de valores estruturantes da vida em sociedade, seja na perspectiva de cada comunidade como no âmbito universal.

De certo modo, a aparente indeterminação conceitual da dignidade humana remete o intérprete ao conceito do próprio homem.

Quem é aquele ser cuja envergadura recebe, como atributo qualificativo, a dignidade?

Só pode ser aquele que usa a humanidade como fim. Isto é, que usa a humanidade como atributo apto à conquista do bem comum.

Desde que a comunidade busque o bem comum como fim último será sempre proibido que se faça do homem mero objeto do Estado ou que se lhe retire a condição subjetiva de decidir por si mesmo sobre seu destino.

FÁBIO COMPARATO põe de manifesto que a pessoa humana, sendo dotada de razão e liberdade, nunca será ou poderá ser tratada como meio. Daí afirmar, com propriedade: 
Ora, a dignidade da pessoa não consiste apenas no fato de ser ela, diferentemente das coisas, um ser considerado e tratado, em si mesmo, como um fim em si e nunca como um meio para a consecução de determinado resultado. Ela resulta também do fato de que, pela sua vontade racional, só a pessoa vive em condições de autonomia, isto é, como ser capaz de guiarse pelas leis que ele próprio edita. (2003, p.21).

A dignidade se retira do terreno da indeterminação, porém, quando aponta para as reais necessidades de cada pessoa. Eis a razão pela qual JORGE MIRANDA (1993, p. 169) sublinha:

[...] a dignidade da pessoa é da pessoa concreta, na sua vida real e quotidiana; não é de um ser ideal e abstracto. É o homem ou a mulher, tal como existe, que a ordem jurídica considera irredutível e insubstituível e cujos direitos fundamentais a Constituição enuncia e protege. Em todo o homem e em toda a mulher estão presentes todas as faculdades da humanidade.

Portanto, a dignidade nada mais consiste do que na concretização dos direitos outorgados pelo ordenamento jurídico, particularmente daqueles explicitamente enunciados na Convenção Americana de Direitos Humanos.

Em suma, tem dignidade todas as pessoas a quem é conferida a plenitude dos direitos humanos.

\section{NATUREZA SOCIAL DA PESSOA HUMANA}

O destino do homem consiste em viver em sociedade.

Essa é a projeção da pessoa, que deve buscar o pleno desenvolvimento de sua personalidade no trato com os demais.

Há uma simbiose perfeita entre a conquista completa dos direitos humanos individuais e a concretização da respectiva dimensão social.

Em um dos documentos mais importantes emitidos pelo Concílio Ecumênico Vaticano II - a Constituição Pastoral Gaudium et Spes sobre a Igreja no Mundo Contemporâneo, assim se acha sintetizada essa simbiose: 


\begin{abstract}
A índole social do homem demonstra que o desenvolvimento da pessoa humana e o crescimento da própria sociedade estão mutuamente condicionados, porque o princípio, o sujeito e o fim de todas as instituições sociais é e deve ser a pessoa humana, a qual por sua mesma natureza tem absoluta necessidade da vida social.(1965, ponto 25).
\end{abstract}

Portanto, a pessoa se relaciona com as demais e com as instituições.

Esse ponto é a chave essencial para que se compreenda tudo o que será sustentado neste estudo.

A vida social é integrada não apenas pelos indivíduos, concretamente considerados na respectiva individualidade - que será sempre respeitada e preservada- como, igualmente, pelas instituições.

$E$, tais instituições, por força de estruturas conceptuais que foram sendo cunhadas pelos distintos ordenamentos normativos, podem adquirir certa personalidade que nada mais consiste do que na projeção dos propósitos e objetivos dos indivíduos que histórica e socialmente as integraram e, presentemente, as integram.

$E$, tais instituições, incumbidas da configuração e do aperfeiçoamento do tecido social, estabelecem entre si, por intermédio dos respectivos integrantes, canais de comunicação que configuram, no decorrer do tempo, natural interdependência, cujo escopo - em homenagem aos Direitos Humanos - consiste no diálogo, na cooperação, na solidariedade.

Naturalmente, há lugares específicos onde a convivência assume características peculiares e, até certo ponto, distintas, como a cooperativa, o sindicato, as associações, as sociedades, as famílias, as escolas, as organizações nãogovernamentais e, ainda, toda e qualquer expressão da liberdade associativa a que se referem os instrumentos internacionais de Direitos Humanos, particularmente a Declaração Universal, de 1948, e o Pacto de San Jose, de 1969.

Portanto, para garantir a plena efetividade dos direitos humanos e para que se intensifique, em favor do bem comum, a integração entre os homens é de toda a conveniência que sejam criados, aperfeiçoados e incrementados os lugares sociais comunitários, nos quais esses distintos coletivos reforcem e ampliem as capacidades das pessoas. 
A natureza social da pessoa humana impõe, por assim dizer, notável ritmo harmônico entre a socialização, reveladora das interdependências e conexões entre pessoas e grupos (como assinalado no já referido ponto 25 da Gaudium et Spes) e a subjetivação, a demonstrar a multiplicidade de atuações do indivíduo e da sociedade.

\section{A LIBERDADE DE ASSOCIAÇÃO}

A liberdade de associação é fórmula assecuratória; trata-se da via apta a permitir o concreto expressar-se da natureza social da pessoa humana.

A associação, ditada pelas mais diferentes circunstâncias, operacionaliza os objetivos comuns - as finalidades - que o grupo agremiado tem em vista.

A associação já é o primeiro resultado da escolha que as pessoas fizeram a respeito dos direitos que querem ver concretizados. Conscientes de que não podem abrir mão do respectivo papel de agentes dos respectivos direitos, os indivíduos configuram a estrutura instrumental que Ihes permitirá por ao vivo suas propostas e objetivos.

Articuladas sob modo associativo, as pessoas se relacionam com a realidade a partir de certa perspectiva institucional. Tal perspectiva, ditada pelos atos constitutivos da entidade, definem, de pronto, o lugar social a partir do qual a entidade pretende atuar.

A associação é meio de ação das pessoas. $O$ ato constitutivo pode bem ser comparado com o script que a "persona" deverá representar. Esse ato não é tão somente um instrumento de trabalho, verdadeiro mandato que os associados outorgam aos respectivos representantes ou dirigentes. É, igualmente, a pauta de direitos que a estrutura associativa se propôs a concretizar.

Os fins, ideológicos, religiosos, políticos, econômicos, trabalhistas, sociais, culturais, desportivos ou de qualquer outra natureza ficam, de pronto, plenamente identificados e explicitados.

Assim proclama o Pacto de San Jose: 
Artigo 16. Liberdade de associação: 1. Todas as pessoas têm o direito de associar-se livremente com fins ideológicos, religiosos, políticos, econômicos, trabalhistas, sociais, culturais, desportivos ou de qualquer outra natureza. 2. 0 exercício de tal direito só pode estar sujeito às restrições previstas pela lei que sejam necessárias, numa sociedade democrática, no interesse da segurança nacional, da segurança ou da ordem públicas, ou para proteger a saúde ou a moral públicas ou os direitos e liberdades das demais pessoas. 3 . 0 disposto neste artigo não impede a imposição de restrições legais, e mesmo a privação do exercício do direito de associação, aos membros das forças armadas e da polícia.

Livres para associarem-se, situando a pauta dos respectivos objetivos nos mais diferentes planos da vida social, as pessoas devem buscar o bem comum.

Com a associação, a pessoa demonstra ter plena consciência de que não se basta a si mesma; de que é parte integrante de um coletivo cujos direitos só podem ser plenamente exercidos sob a perspectiva comunitária.

Ao agir com e para os demais, a pessoa associada acrescenta à respectiva personalidade mais um elemento de mobilização rumo ao concretizar dos direitos humanos, ajuntando uma segunda potência ao cabedal de dignidade com que já se situa no mundo.

\section{O FENÔMENO ASSOCIATIVO}

O atual momento histórico é caracterizado pelo incremento do fenômeno associativo.

Às antigas formas de associação, que sempre ocuparam papel de destaque na vida social, como são os sindicatos e as cooperativas, acrescentou-se a modelagem aberta das assim chamadas "organizações não-governamentais".

A Carta das Nações Unidas dá destaque especial a essa expressão do fenômeno associativo quando estatui, no art. 71 que: 
O Conselho Econômico e Social poderá entrar em entendimentos para consultar organizações não-governamentais que se ocupem de assuntos no âmbito da sua própria competência. Tais entendimentos poderão ser feitos com organizações internacionais e, quando for o caso, com organizações nacionais, depois de efetuadas consultas com o membro das Nações Unidas interessado no caso.

A esses importantes atores tem sido reservado significativo papel no alargamento do âmbito de incidência dos Direitos Humanos, como bem percebeu Norberto Bobbio (1993, p. 68) ao afirmar que isso ocorre: "b) porque foi estendida a titularidade de alguns direitos típicos a sujeitos diversos do homem;"

Temas vários acrescentaram-se à tradicional concepção dos Direitos Humanos e sobre os mesmos essas novas formas organizativas tem atuado de modo intenso e eficiente.

Assim se pode situar a questão demográfica, a questão ambiental, a paz, a erradicação da pobreza, o desarmamento, o terrorismo, o desenvolvimento e outras tantas abordagens que poderiam ser inventariadas num relance.

Cada uma dessas entidades, somadas às já tradicionais, buscam assumir a posição estratégica de agentes dos Direitos Humanos.

Será, talvez, necessário o estabelecimento de uma ordem de prioridades na extensa pauta de construção dos direitos humanos.

Mas, não se pode ignorar que certo lugar há de estar reservado a certas instituições que, além do indivíduo, também exercitam a titularidade dos Direitos Humanos.

\section{NÃO SÃO SOMENTE AS PESSOAS FÍSICAS OBJETO DA COBERTURA DA CONVENÇÃO AMERICANA SOBRE DIREITOS HUMANOS}

Os valores que constituem a dignificação da pessoa humana tiveram, no seu nascedouro, que ser postos à prova nos estritos limites da individualidade.

Cuidava-se, então, de garantir a liberdade, atributo inerente à condição humana, diante dos brutais fenômenos de violação desse valor, dos quais se destaca o mais violento de todos que foi o da escravidão. 
Do mesmo modo, importava, naquele nascedouro, garantir a igualdade, impeditiva de toda e qualquer discriminação, notadamente aquelas estatuídas pelas diferenças de raça, de cor, de sexo, de língua, de religião, de opinião política, dentre outras.

A dignidade da pessoa humana, cerne dos direitos humanos, guarda como um artigo de fé a igualdade e a liberdade, como acentua o Preâmbulo da Declaração de 1948.

Do mesmo modo, rimando com o Preâmbulo, o art. VI da Declaração Universal define a pessoa como a conjugação concreta da liberdade com a igualdade. É pessoa aquele que os demais consideram como um igual e a quem se assegura a liberdade em toda a sua extensão.

O Pacto de San Jose faz igual profissão de fé ao afirmar, em linguagem lapidar:

2. Para efeitos desta Convenção, pessoa é todo ser humano.

Segundo a célebre resposta ao quesito 29, na Suma Teológica TOMAS DE AQUINO (1980, p. 129): a pessoa é uma substância individual de natureza racional.

A dignidade manifesta a identidade da pessoa. Todo o homem deve reconhecer o outro como pessoa, pois como assinala BARZOTO (2010, p. 29): "A dignidade é assim, o valor positivo e objetivo de uma identidade."

O que devemos ter presente é a impossibilidade de ampliação do conceito de pessoa para além dos limites do ser do homem, no contexto limitado do artigo em comento.

Aqui, mas não apenas aqui, se está diante de alguém, um sujeito, dotado de certa natureza como tal reconhecida pelos demais, independentemente da interposição de qualquer credencial jurídica.

Sublinhe-se, com duplo sublinhado:

Nesse sentido, o homem é o artífice ou o artista de si mesmo e sua primeira obra de arte que para a imensa maioria é a única - aquela cuja feitura se prolonga para cada um ao longo de toda a vida - é a sua própria existência como homem (LIMA VAZ, 1992, p.217). 
Ora a personalização criada pelo Direito depende do instrumental normativo, este sim expressão da vontade coletiva, do conjunto de pessoas que compõe a sociedade organizada em Estado.

Assim, o aparelho do Estado cria não só um paradigma novo de pessoa, a pessoa jurídica, como, igualmente, configura as tarefas que essa pessoa pode desempenhar na estrutura social e nas relações humanas, inclusive aquelas nas quais se situam os Direitos Humanos.

Ergo, o Parágrafo Segundo, na sua interpretação estrita, restringe a proteção interamericana dos direitos humanos às pessoas físicas.

Entretanto, não resultam excluídas do âmbito de aplicação da Convenção as pessoas jurídicas. O fundamento normativo que alberga as pessoas jurídicas na esfera de incidência da Convenção é o artigo 16 do mesmo Diploma Americano, como se verá a seu tempo.

\section{DEMAIS PERSONALIDADES QUE TAMBÉM PODEM SER CONSIDERADAS COMO SUJEITOS DE DIREITOS HUMANOS.}

Não se confundem os direitos inerentes à pessoa humana, vale dizer, ao ser do homem, ao ser em si e unicamente em si considerado, com os predicados que podem ser imputados ao homem.

É de manifesta claridade o preceito estampado no Art. VI da Declaração Universal dos Direitos Humanos: "Todo homem tem o direito de ser, em todos os lugares, reconhecido como pessoa perante a lei".

O reconhecimento da personalidade do homem é a ele inerente, como Direito Humano.

Do mesmo modo, incumbe ao direito, mas não ao Direito dos Direitos Humanos, institucionalizar realidades jurídicas que possam cooperar no atingimento dos objetivos da pessoa humana.

A ratio motivadora da criação das pessoas jurídicas é assim enunciada por Silva Pereira (2000, p. 185): 
[...] a necessidade da conjugação de esforços de vários indivíduos para a consecução de objetivos comuns ou de interesse social, ao mesmo passo que aconselham e estimulam a sua agregação e polarização de suas atividades, sugerem ao direito equiparar à própria pessoa humana certos agrupamentos de indivíduos e certas destinações patrimoniais e the aconselham atribuir personalidade e capacidade aos entes abstratos assim gerados.

Desde logo, o notável pensador explicita: o direito as equipara às pessoas humanas para, desse modo, atribuir-Ihes personalidade e capacidade.

Ao conferir personalidade a tais pessoas a normatividade imprime, de pronto, certo objetivo ou finalidade ao agir desses entes.

O objetivo de tais entidades, no âmbito especifico de que aqui nos ocupamos, consiste em proporcionar o pleno exercício dos Direitos Humanos das pessoas que as integram.

Existem, pois, as pessoas jurídicas - quando constituídas para a defesa dos Direitos Humanos - como verdadeiras projeções formais das pessoas humanas cujos direitos Ihes incumbe concretizar.

Tais sujeitos de direitos operam tão somente dentro dos fins que thes foram adrede ordenados.

O encargo que Ihes foi confiado, em vista do bem de seus associados, é exercido como expressão dos atributos que compõe a índole das pessoas humanas que as integram.

Dotados de capacidade, tais entes podem atuar na defesa dos Direitos Humanos de seus integrantes.

Mas, cumpre manter em retentiva, que os Direitos Humanos não pertencem à pessoa jurídica. São fruíveis individual ou coletivamente pelas pessoas humanas e tão somente por estas.

Cooperam, destarte, as pessoas jurídicas para conferir máxima efetividade aos Direitos Humanos de cada um dos integrantes do gênero humano que as conformaram segundo a modelagem normativa. 
Portanto, o objetivo da existência de tais pessoas jurídicas consiste em, como assinala FRANCESCHET (2008, p. 139): fortalecer a proteção da pessoa humana através da cláusula geral de pleno desenvolvimento de suas potencialidades [...].

A organização coletiva dos sujeitos de Direitos Humanos, como fórmula de outorga de máxima efetividade a tais direitos será outra arma com que a normatividade operará em favor da comunidade protegida e de seus integrantes individualmente considerados.

Cooperam, destarte, as pessoas jurídicas para conferir máxima efetividade aos Direitos Humanos de cada um dos integrantes do gênero humano que as conformaram segundo a modelagem normativa.

Desse modo, sendo os Direitos Humanos o rol de atributos a que a normatividade confere a tarefa incomensurável de proteger, em toda a sua extensão, a dignidade da pessoa humana - valor-fonte da ordo iuris - todos os caminhos serão revestidos de legitimidade para que se atinja tal desiderato.

Congregados na pessoa jurídica que houveram por bem constituir, como manifestação inequívoca de outra etapa na busca incessante pelos Direitos Humanos, as pessoas humanas podem impetrar a tutela a que fazem jus.

Ninguém poderá duvidar que, em cada atitude processual que a pessoa jurídica tiver que tomar estará projetando tão somente a índole dos Direitos Humanos de seus integrantes que, para tanto, lhe outorgaram o ser de direito.

A personalização de tais entidades só teria sentido, aliás, na medida em que dessa construção formal decorresse a melhor funcionalização dos Direitos do homem que as constituiu.

Em que consiste, pois, a personalidade jurídica outorgada a essas entidades cuja razão de existir é a defesa dos Direitos Humanos? No puro e simples suporte do reconhecimento e efetivação de tais direitos. São elas, destarte, centros de imputação dos Direitos Humanos.

A capacidade derivada da personalidade jurídica conferida a tais pessoas consiste na possibilidade efetiva de assumirem a titularidade, em nome e por conta de seus integrantes, dos Direitos Humanos. 
Força reconhecer, por conseguinte, que as cooperativas, os sindicatos, as associações e as sociedades são, igualmente, protegidas pela Convenção, na exata medida em que se constituem em correias de transmissão dos Direitos Humanos das pessoas que delas fazem parte integrante.

7. A titularidade dos direitos em perspectiva processual.

As organizações representativas dos sujeitos titulares de Direitos Humanos estão plenamente habilitadas a acudir aos procedimentos da jurisdição interna e a esgotar os recursos da jurisdição interna.

Tal posição processual decorre do dever associativo que lhes incumbe, verdadeiro e próprio mandato de que se acham investidas ipso facto pela respectiva criação e vivência.

Trata-se, mais especificamente, de direito que constitui mera projeção dos Direitos Humanos de seus integrantes e de um múnus institucional que confere efetividade ao agir para o qual foram, a seu tempo, legalmente constituídas.

\section{DIREITOS QUE PODEM SER RECONHECIDOS A PESSOAS JURÍDICAS OU COLETIVAS}

Conquanto não seja, aqui, o lugar de enumeração de toda a gama de direitos suscetíveis de tutela em favor das pessoas jurídicas, pode-se afirmar, brevitatis causa, que não podem existir restrições ao exame de situações que venham a ofender, restringir ou macular os direitos humanos.

Consoante a lição - que para os Direitos Humanos consiste em preceituário - da Declaração e Programa de Ação de Viena, formulada pela Conferência Mundial sobre Direitos Humanos realizada em 1993: 


\begin{abstract}
5. Todos os Direitos Humanos são universais, indivisíveis, interdependentes e interrelacionados. A comunidade internacional deve considerar os Direitos Humanos, globalmente, de forma justa e equitativa, no mesmo pé e com igual ênfase. Embora se deva ter sempre presente o significado das especificidades nacionais e regionais e os diversos antecedentes históricos, culturais e religiosos, compete aos Estados, independentemente dos seus sistemas políticos, econômicos e culturais, promover e proteger todos os Direitos Humanos e liberdades fundamentais
\end{abstract}

Deste modo, a hermenêutica dos Direitos Humanos consiste em considerar esse Bill como dotado de indivisibilidade.

Daqui parece resultar que a formulação pontual dos Direitos Humanos poderia truncar ou mesmo desfalcar a compreensão do conjunto na respectiva integridade.

O corte que se faz, tendo em vista os termos em que foi vazado o questionamento, visa construir mero esquema abstrato, restrito ao âmbito da Consulta.

Deste modo, é aplicável às pessoas jurídicas o direito à proteção judicial e ao devido processo, previsto no artigo 8 da Convenção Americana de Direitos Humanos.

Em que consiste a garantia do devido processo?

$\mathrm{Na}$ dimensão especificamente jurídica com que as Cartas de Direitos Humanos - dentre as quais se inclui a Convenção - qualificam o instrumento processual.

Todas as relações jurídicas que nascem, são mantidas e se extinguem no âmbito dos Direitos Humanos se conformam através de um procedimento.

Ao inserir na Convenção a conhecida cláusula do devido processo legal, a comunidade americana reconheceu tal atributo como instrumento de articulação dos Direitos Humanos.

Todos os Direitos Humanos devem ser adjudicados mediante certo processo de outorga. Esse processo determina o encadeamento rigoroso em que deve se dar o reconhecimento de tais Direitos.

Todo e qualquer ato que reconhece um direito à pessoa é, por si mesmo, manifestação do cânon do devido processo legal. Pode-se afirmar que o devido processo é o iter de produção do ato que adjudica tal direito. 
CARLOS ROBERTO DE SIQUEIRA CASTRO sublinha que são, na atualidade, duas as dimensões do devido processo. A primeira é a de natureza substantiva (substantive due process) enquanto que a segunda é a de natureza instrumental (procedural due process).

Em diversos julgados emanados da Suprem Court of the United States o referido autor demonstra a evolução da cláusula. Hoje em dia, a cláusula se situa, para além do terreno processual penal no qual nascera, na esfera do direito material.

Logo, a cláusula significa, em nossos dias, no dizer desse autor (1989, p. 34): [...] o "princípio vetor das manifestações do Estado contemporâneo e das relações de toda ordem entre o Poder Público, de um lado, e a sociedade e os indivíduos, de outro."

De certo modo, as garantias constitucionais nascidas a partir da exegese da Constituição norte-americana se subordinam a uma dinâmica peculiar.

Como que abrindo a primeira via para a reconfiguração do devido processo em sua dimensão material, o Justice Douglas, no ousado dissenso que proferiu a respeito do case Sierra Club versus Morton já alertava:

Inanimate objects are sometimes parties in litigation. A ship has a legal personality, a fiction found useful for maritime purposes. The corporation sole - a creature of ecclesiastical law - is an acceptable adversary and large fortunes ride on its cases. The ordinary corporation is a "person" for purposes of the adjudicatory processes, whether it represents proprietary, spiritual, aesthetic, or charitable causes (.405 U.S. 727 (1972).

Aliás, o mesmo Magistrado já assinalara (1976, p. 71) que: "os princípios da Carta de Direitos, são partes da estrutura diária das nossas vidas em uma proporção muito maior do que a maioria de nós reconhece.".

Estão em permanente mutação os princípios, visto que se acham postos sob a influência da vida jurídica.

A diretriz do devido processo é de ser reconhecida como critério de admissibilidade das partes em causas onde os Direitos Humanos devam ser apreciados. 
Essa perspectiva atual permite que se considere a cláusula como critério processual por excelência para a admissão de distintos sujeitos no âmbito das causas de Direitos Humanos.

Aliás, coincidente com esse pensar NELSON NERY JÚNIOR (1992, p. 25) assinala que tal princípio deve ser havido como: "o gênero do qual todos os demais princípios constitucionais do processo são espécies."

Reforçando a própria noção de igualdade e não discriminação, expressamente cominadas nos artigos 1.1 e 24 da Convenção, o devido processo confere plenitude à representação das partes nos casos em que os Direitos Humanos sejam apreciados.

Para assegurar a igualdade, o devido processo poderá exigir o chamamento à lide de todos os interessados em determinada questão. Isto é, de todos aqueles cujos Direitos Humanos possam vir a ser afetados pela decisão que venha a ser apreciada naquela determinada causa.

Portanto, com isso já adianto que a igualdade é verdadeiro princípio geral do Direito aplicável assim às pessoas naturais como às pessoas jurídicas. E o seu corolário natural, a não discriminação, também deve ser considerado como parte integrante dos direitos tanto das pessoas humanas quanto das pessoas jurídicas que defendem os direitos humanos.

É bem verdade que o princípio do devido processo legal se acha explicitado na Convenção.

Mas mesmo que não estivesse expressamente lançado naquele Texto Normativo deveria ser considerado como regra implícita a qualquer processo.

Em realidade, os Direitos Humanos são universais. E mais não faz a garantia do devido processo do que admitir a todos os interessados como partes integrantes das demandas que versem sobre tão abrangente temática.

O direito à intimidade e à vida privada configuram a fortificação necessária para que a defesa dos Direitos Humanos seja preservada de quaisquer ingerências externas que pretendam ou intentem violenta-los. 
Assim, a correspondência, o conteúdo dos debates levados a efeito em assembleia e outras tantas atividades que condizem com a estratégia de atuação da entidade, em defesa dos Direitos Humanos de seus integrantes devem ser, a todo o custo, formalmente protegidas.

A liberdade de expressão é natural corolário do direito de associação. Assim os associados quanto a entidade que, com legitimidade, os representa, terão assegurado o exercício regular desse Direito Humano.

O direito de propriedade integra a ordem natural das coisas. Pertence, por direito próprio, à pessoa humana. Como natural projeção do direito de associação, as entidades que congregam as pessoas na defesa de seus direitos podem constituir patrimônio apto a suportar os ônus econômicos dos embates que devem travar no estrito cumprimento de sua missão associativa.

Sobre a igualdade muito poderia ser dito.

É, a seu modo, direito que emana da ordem natural, tal como concebida pela superior sabedoria do Criador.

Ganha formato, sob tal inspiração, no contexto normativo da comunidade humana a partir da diretriz expressa no artigo I da Declaração Universal dos Direitos do Homem, aprovada pelas Nações Unidas em 10 de dezembro de 1948, e incorporada ao direito dos povos em inumeráveis Constituições.

Destarte, o preceito contido na Convenção se perfila, em plenitude axiológica, com a ordo iuris do mundo civilizado.

Dado que os homens não são iguais, posto que cada qual está sujeito ao meio de realidades sociais, econômicas e culturais em que vive está sujeito a distintas situações de risco (e é para ampara-lo nessas situações que existem os Direitos Humanos) as regras jurídicas devem operar a fim de que ocorra a redução das desigualdades individuais, sociais e humanitárias.

Pode-se dizer, até mesmo, que a isonomia atingiu, no dealbar do terceiro milênio, o cume de sua projeção histórica.

Isso por ser a isonomia, bem notou FRANCISCO CAMPOS (1956, p. 45) em texto clássico sobre o tema: "[...] a garantia suprema, ou a garantia que em última instância assegura e garante as garantias particulares." 
A estruturação das normas que regerão todo o cardápio dos Direitos Humanos parte da ideia de isonomia como um pressuposto, verdadeira categoria de pensamento.

O fundamento de validade e de legitimidade do agir dos órgãos de tutela dos Direitos Humanos, inclusive e especialmente a Corte Interamericana de Direitos Humanos é a isonomia, que proíbe toda e qualquer discriminação que reduza a dignidade e a paridade entre as pessoas humanas.

As entidades que defendem os Direitos Humanos, em estrita observância de seus atos constitutivos, devem operar sob condições de igualdade tanto defronte às demais entidades quanto aos órgãos públicos ou estamentos judiciais a que tenham que recorrer na defesa dos direitos de seus integrantes.

Como bem lembram Celso Bastos e Gandra Martins (1989 p.5): Em muitas hipóteses a proteção última ao indivíduo só se dá por meio da proteção que se confere às próprias pessoas jurídicas

Assim, por exemplo, quando o sujeito de direitos - assim a pessoa natural como a pessoa jurídica que congrega os titulares de direitos - se vê na contingência de acionar a máquina jurídica para obter o reconhecimento de seu direito, a utilização da estrutura processual, formalmente constituída, permitirá que se lhe reconheça, em igualdade de condições com os demais membros do coletivo protegido, isonomia.

A regra de igualdade se transforma, assim, na mais objetiva expressão dos Direitos Humanos catalogada no interior dos sistemas jurídicos. Terão, as estruturas de apreciação dos Direitos Humanos a obrigação jurídica de proporcionar quantidade de proteção material e processual suficiente a quem delas necessitar.

A greve é, por sua própria natureza, um direito que expressa o querer e o agir de certa comunidade de pessoas.

Deflagrada a partir de ações ou omissões que atingem, afetam ou prejudicam os Direitos Humanos Sociais, a greve ganha legitimidade na medida em que aqueles que se perfilam em torno de determinada causa definem, com precisão, os objetivos que o movimento pretende ver atingidos. 
As entidades que congregam os direitos dos trabalhadores, particularmente os sindicatos, as federações e as confederações, são constituídas em homenagem ao valor da liberdade sindical, consagrado em diferentes instrumentos de Direitos Humanos, particularmente na Constituição da Organização Internacional do Trabalho, na Declaração dos Direitos Humanos, de 1948, no Pacto dos Direitos Econômicos, Sociais e Culturais, de 1966 e no Protocolo de San Salvador.

Temos que, com fundamento no Artigo 16, da Convenção, as pessoas jurídicas possuem direito à igualdade e à não discriminação, estampados nos artigos 1 e 24, da Convenção; à liberdade de associação, de que cuida o art. 16; à intimidade e à vida privada, nos termos do Artigo 11; à propriedade privada, qualificada pelo Artigo 21, todos do Pacto de San Jose.

Sob a perspectiva processual estão asseguradas, nos termos dos Artigos $8 \mathrm{e}$ 25 da Convenção Americana.

Se a defesa dos Direitos Humanos se prende com o caráter necessário e absoluto de tais direitos, todos os meios idôneos de que a inventiva jurídica lance mão para a salvaguarda de tais direitos devem ser havidos como legítimos.

É que, todos esses meios, se acham informados pela intenção da universalidade dos Direitos Humanos e da máxima efetividade que há de se imprimir a essa cópia de Direitos conquistada e afirmada historicamente.

Por conseguinte, as estruturas instrumentais do direito - e, ao fim e ao cabo, é disso que se cuida aqui - devem ser postas a serviço da conquista das posições mais avançadas que as pessoas, as comunidades e, enfim, toda a sociedade humana hão de atingir na era dos Direitos Humanos.

\section{OS ESTREITOS LIMITES DA JURISDIÇÃO INTERNA}

As pessoas jurídicas estão revestidas de plena legitimidade para proporem, iure proprio, o que entenderem pertinente à defesa dos Direitos Humanos de seus integrantes. 
Essa regra é aplicável independentemente da fórmula jurídica constitutiva da pessoa jurídica.

Ressalta à evidência que as pessoas jurídicas auferem, como sublinha TEPEDINO (1999, p. 52) a: "[...] tutela jurídica apenas e tão-somente como instrumento (privilegiado) para realização das pessoas que, em seu âmbito de ação, é capaz de congregar. "

A atuação das pessoas jurídicas vai toda ela endereçada a realizar os Direitos Humanos de seus integrantes.

É revestida dessa função instrumental que a pessoa jurídica participa do processo histórico, político e social de concretização dos Direitos Humanos.

Essa regra é aplicável independentemente da fórmula jurídica constitutiva da pessoa jurídica.

Naturalmente, os atos constitutivos poderão ordenar que se realize assembleia específica da entidade a fim de que o coletivo outorgue à pessoa jurídica o mandato - fórmula de expressão da vontade do grupo - para que atue nesta ou naquela direção na defesa dos Direitos Humanos do grupo protegido.

Não obstante, cada um dos integrantes da pessoa jurídica poderá atuar de modo isolado, sem que esse agir configure, na seara dos Direitos Humanos, sem qualquer prejuízo da intencionalidade processualmente operante da pessoa jurídica.

Destarte, uma empresa ou sociedade privada, seja ela a cooperativa, a sociedade civil ou comercial, o sindicato, um meio de comunicação social ou uma organização indígena, pode esgotar os recursos da jurisdição interna e, depois, propor o que de direito perante a Comissão Interamericana de Direitos Humanos, assim como seus integrantes, de modo individual, poderá propor as medidas pertinentes em sua qualidade singular de pessoa física. 
Como se tem afirmado aqui, incumbe ao Direito dos Direitos Humanos reconhecer, sempre e em todo o lugar, a qualidade essencial de que se acham revestidas as pessoas humanas - o homem todo e todos os homens, na feliz expressão empregada na Populorum progressio por PAULO VI (2006, p. 42) - do papel essencial de agentes da história e de promotores naturais do processo de dignificação das pessoas em que consiste a outorga, melhor dizendo, o reconhecimento dos Direitos Humanos.

Incumbe à pessoa humana, em primeiríssimo lugar, o papel diretor dos aconteceres, em tema de Direitos Humanos.

As instituições, notadamente as pessoas jurídicas, podem conformar-se com os esquemas rígidos impostos pelas limitações territoriais da respectiva atuação, ditada pelos atos que Ihes conferiram personalidade.

A pessoa humana há de ajustar o seu agir de conformidade com a resultante de Direitos Humanos que pretende seja concretizada em seu favor.

Representaria o esvaziamento do Bill de Direitos Humanos o impedimento do acesso da pessoa humana às Cortes, particularmente a Corte dos Direitos Humanos, a denegação de certo pleito por força de escudos formais de rejeição concebidos à luz de civilisticas e processualísticas concepções do jurídico. Vale dizer, esquemas que tenham como suporte uma lógica puramente formal que, forçosamente, deixa de lado a normatividade inerente a esse catálogo sui generis de direitos.

\section{O ESGOTAMENTO DOS RECURSOS INTERNOS}

A exigência de esgotamento dos recurso internos, em tema de Direitos Humanos é de ser entendida como fórmula apta a permitir que os Estados, tomando conhecimento de situações de violação, no regular exercício do múnus público de defesa do bem comum - como enuncia sinteticamente o art. 3ํ da Constituição do Brasil, incumbe a essa República Federativa "promover o bem de todos, sem preconceitos de origem, raça, sexo, cor, idade e quaisquer outras formas de discriminação" - resolva o quanto antes em favor dos Direitos Humanos. 
Trata-se, pois, de homenagem que se presta ao Estado, entendido como o lugar natural de proteção do direito das pessoas que dele fazem parte.

Tendo em vista os rígidos termos do art. 46 da Convenção o que importa é ter existido o acionamento oportuno dos canais de apreciação interna dos pleitos de Direitos Humanos.

Essa regra não distingue, segundo nos parece, a pessoa física da pessoa jurídica.

Qualquer um deles pode demonstrar haver percorrido o iter processual de apreciação do case no âmbito interno do Estado no qual ocorreram os fatos que se quer trazer à apreciação da Corte.

Advirta-se, ainda uma vez mais, que essa regra não deve ser assumida com o viés formalista com que, muita vez, os institutos processuais são encarados.

É, aliás, o que esclarece a alínea 2 do art. 46 da Convenção Americana ao dispor in verbis:

2. As disposições das alíneas "a" e "b" do inciso 1 deste artigo não se aplicarão quando: a) não existir, na legislação interna do Estado de que se tratar, o devido processo legal para a proteção do direito ou direitos que se alegue tenham sido violados; b) não se houver permitido ao presumido prejudicado em seus direitos o acesso aos recursos da jurisdição interna, ou houver sido ele impedido de esgotá-los; e c) houver demora injustificada na decisão sobre os mencionados recursos.

Talvez se pudesse começar pelo fim.

O esgotamento dos recursos internos não se comprova pura e simplesmente porque o Estado não decide nada.

A demora injustificada, o silêncio, no caso, soa e ecoa como denegação cabal do direito.

A ausência do devido processo - garantia essencial dos direitos humanos, como já se acentuou neste estudo - é porta aberta ao arbítrio, incompatível com o preceituário garantidor de direitos que incumbe à Corte apreciar. 
Finalmente, a denegação do acesso à Justiça que, nas mais das vezes, se deve a compreensão obtusa do fenômeno processual, de que também já se tem tratado aqui.

Ergo, os Direitos Humanos configuram sistema coerente de proteção das pessoas, pacientemente engendrado pela comunidade internacional.

Não é possível apequenar a compreensão e aplicação dos Direitos Humanos mediante o recurso a uma formalística exagerada que desserve ao Direito. Forma dat esse rei, dizia o emblemático aforismo dos romanos.

Essa regra não pode ser aceita no universo sensível dos Direitos Humanos dentro no qual é o conteúdo, envolvido pelo fio condutor da dignidade da pessoa humana, que dá ser às coisas.

Portanto, a diretriz de esgotamento dos recursos internos, como tudo o mais nos quadrantes dos Direitos Humanos, está posta sob a perspectiva essencialmente protetora em que se situa o Sistema de Direitos Humanos.

É, por conseguinte, de todo indiferente à compreensão do cumprimento do requisito o saber-se de quem tenha partido a iniciativa processual.

\section{CONCLUSÃO}

A pessoa jurídica exerce, em nome próprio e no de seus integrantes, os Direitos Humanos, sendo, portanto, titular do respectivo Direito Subjetivo.

Assim, sendo a pessoa jurídica sujeito de Direitos Humanos, titular do respectivo Direito Subjetivo, ela, a um só tempo, é participe ativa e beneficiária da ordem jurídica de Direitos Humanos.

Logo, cabe à pessoa jurídica observar os Direitos Humanos, em seu favor, mas, também, em face dela. Os efeitos jurídicos disto, geram uma singularidade quântica de direitos e obrigações de Direitos Humanos para a pessoa jurídica, edificando, no âmbito empresarial, a Dimensão Econômica dos Direitos Humanos, a qual chamamos de Capitalismo Humanista, que emerge do respectivo desvendar quântico, como investigamos e esclarecemos na obra Fator $\mathrm{CapH}$. 


\section{REFERÊNCIAS}

AQUINO, Tomas de. Suma Teológica, Volume I, Rio Grande do Sul: Livraria Sulina Editora, 1980, tradução de Alexandre Corrêa.

BARZOTTO, Luís Fernando. Filosofia do Direito. Os conceitos fundamentais e a tradição jusnaturalista, Porto Alegre: Livraria do Advogado, 2010.

BASTOS, Celso Ribeiro; MARTINS, Ives Gandra. Comentários à Constituição do Brasil. São Paulo: Saraiva, $2^{\underline{a}}$ edição, 1989.

BOBBIO, Norberto. A era dos direitos. Tradução. de Carlos Nelson Coutinho. Rio de Janeiro: Campus, 1992.

CAMPOS, Francisco. Direito Constitucional, São Paulo: Freitas Bastos, 1956, vol.II.

VATICANO II: mensagens, discursos e documentos. Constituição Pastoral Gaudium et Spes sobre a Igreja no Mundo Contemporâneo. São Paulo: Paulinas. 1998. Tradução de Francisco Catão.

DOUGLAS, Willian. Uma Carta Viva de Direitos, São Paulo: IBRASA, $2^{\text {a }}$ edição, 1976, tradução de Wilson Rocha.

FRANCESCHET, Júlio César. Pessoa jurídica e direitos da personalidade. In: ALVES, Alexandre Ferreira de Assunção. Temas de direito civil-empresarial. Rio de Janeiro: Renovar, 2008.

KANT, Immanuel. Fundamentação da Metafísica dos Costumes. São Paulo: Editora Abril, Col. Os Pensadores, 1980, Tradução de Paulo Quintela.

KONDER COMPARATO, Fábio. A afirmação histórica dos direitos humanos, São Paulo: Saraiva, terceira edição, 2003,

LIMA VAZ, Henrique Cláudio de. Antropologia Filosófica II. Coleção Filosofia - 22, São Paulo: Edições Loyola, 1992.

MIRANDA, Jorge. Manual de Direito Constitucional. tomo IV, Coimbra: Coimbra Editora, segunda edição, 1993,

NERY JÚNIOR, Nelson. Princípios do Processo Civil na Constituição Federal. São Paulo: RT, 1992.

PAULO VI, Carta Encíclica Populorum progressio, sobre o desenvolvimento dos povos, de 26 de março de 1967. São Paulo: Paulus, 13ª edição, 2006. 
PEREIRA, Caio Mário da Silva. Instituições de Direito Civil. vol. I. 19ª Ed. Forense. Rio de Janeiro. 2000.

SIQUEIRA CASTRO, Carlos Roberto de. O Devido Processo Legal e a Razoabilidade das Leis na Nova Constituição do Brasil. Rio de Janeiro: Forense, $2^{\mathrm{a}}$ edição, 1989.

TEPEDINO, Gustavo, A tutela da personalidade no ordenamento civilconstitucional brasileiro, em Temas de Direito Civil. Rio de Janeiro: Renovar, 1999. 